\title{
12-year retention of stimulus and schedule control
}

\author{
JOHN W. DONAHOE and DAVID P. MARRS \\ University of Massachusetts, Amherst, Massachusetts 01002
}

\begin{abstract}
After having initially been trained for a classroom demonstration, a pigeon was tested for retention following a 12-year period without intervening training. Strong evidence was obtained of stimulus control and substantial evidence was found of schedule control by the fixed-interval and fixed-ratio components of the multiple schedule used in initial training.
\end{abstract}

We report here findings from a serendipitous opportunity to assess the retention of stimulus and schedule control of an operantly conditioned response. The opportunity arose when a pigeon, originally trained for a classroom demonstration, was maintained as a laboratory pet over an extended period of time.

\section{METHOD}

\section{Subject}

The single subject was a male White Carneaux pigeon whose age was approximately 1 year at the time of original training. The pigeon, hereafter referred to as "Henry," was maintained at $80 \%$ of free-feeding weight during training and testing and at free-feeding weight during the retention interval.

\begin{abstract}
Apparatus
In order to conduct a classroom demonstration for an undergraduate course in learning, an operant chamber was constructed with two walls and the ceiling made from half-silvered plastic. When the chamber was illuminated, the interior was readily visible from a darkened room. The remaining walls, save one, and the floor were constructed of plywood painted black. The fourth wall was formed by a standard intelligence panel (Lehigh Valley Electronics) containing a response key mounted above an opening in which Purina Pigeon Chow could be made accessible via a feeder. The key could be transilluminated with green or red light. A houselight was mounted centrally at the top of the intelligence panel, and a fan provided a masking noise.

Experimental events were programmed and responses were monitored by electromechanical equipment. The equipment was located in an adjacent room during original training and immediately next to the chamber during subsequent testing.
\end{abstract}

\section{Procedure}

In spring, 1969, Henry was given feeder and keypeck training and then placed on a multiple schedule of reinforcement. When the key light was green, a fixed-interval (FI) 60 -sec schedule was operative; when the key light was red, a fixed-ratio (FR) schedule of 40 keypecks to one reinforcer was operative. Reinforcement consisted of 3-sec access to Purina Pigeon Chow. Henry received approximately $20 \mathrm{~h}$ of exposure to the multiple schedule with

The research was supported by NIMH Grant MH-28610 and a biomedical research support grant to the University of Massachusetts. Appreciation is expressed to Kimberly Smith for experimental assistance. Reprints may be obtained from John W. Donahoe, Department of Psychology, University of Massachusetts, Amherst, Massachuset ts 01003. asystematic alternations of blocks of FI $60 \mathrm{sec}$ and FR 40 separated by periods during which the key was dark and extinction was scheduled. No records remain of performance during this period, although response patterns characteristic of FI and FR schedules were obtained for the in-class demonstrations.

Because the behavior of both students and teaching assistants had been reinforced by Henry's orderly data, the assistants (Jerry Collins and Jim Couch) did not "sacrifice" Henry after the demonstration but, rather, kept him housed in a separate cage in the colony room. Although the intention was to use Henry for demonstrations in subsequent semesters, the intelligence panel was needed for other purposes and, with time, additional components were cannibalized from the operant chamber. Henry remained in the laboratory, however, long after his trainers had departed, and he transferred his affections to the animal caretakers, who occasionally freed him from his home cage to fly about the room as they carried out their chores. In fact, Henry became able to slide back the bolt fastening his cage door and to free himself. During a 12-year period, Henry received no further training in any experimental chamber.

In spring, 1981, it was again decided to arrange a pigeon demonstration for the undergraduate learning course. The operant chamber used in the original training was reassembled, and Henry was deprived and placed in the chamber for one session of 10 noncontingent reinforcers in the presence of a dark key prior to the test of retention. After an additional three noncontingent reinforcers in the classroom, the red key light was illuminated for the first time in 12 years and Henry was permitted to complete four cycles of FR 40. In order to study retention more systematically, the classroom demonstration was terminated and a test session was conducted in the laboratory on the following day. The test session consisted of exposure to three noncontingent reinforcers (dark key light), 15 cycles of FI $60 \mathrm{sec}$ (green key light), 15 cycles of FR 40 (red key light), 10 cycles of FI 60 sec (green key light), and 10 cycles of FR 40 (red key light). The blocks of FI and FR schedules were separated by periods of extinction of variable length (mean $=200 \mathrm{sec})$, during which the key was dark. Thus, except for the first exposure to a schedule, essentially a relearning or savings method was used to assess retention.

As a measure of asymptotic performance against which to compare retention, Henry was given 15 additional training sessions with alternating blocks of FI and FR schedules. Cumulative records made during the retention test and during the retraining session provided the major measures of performance.

\section{RESULTS}

The results are first presented as they relate to stimulus control by the illuminated key and then as they relate to control by the FI and FR schedules. 

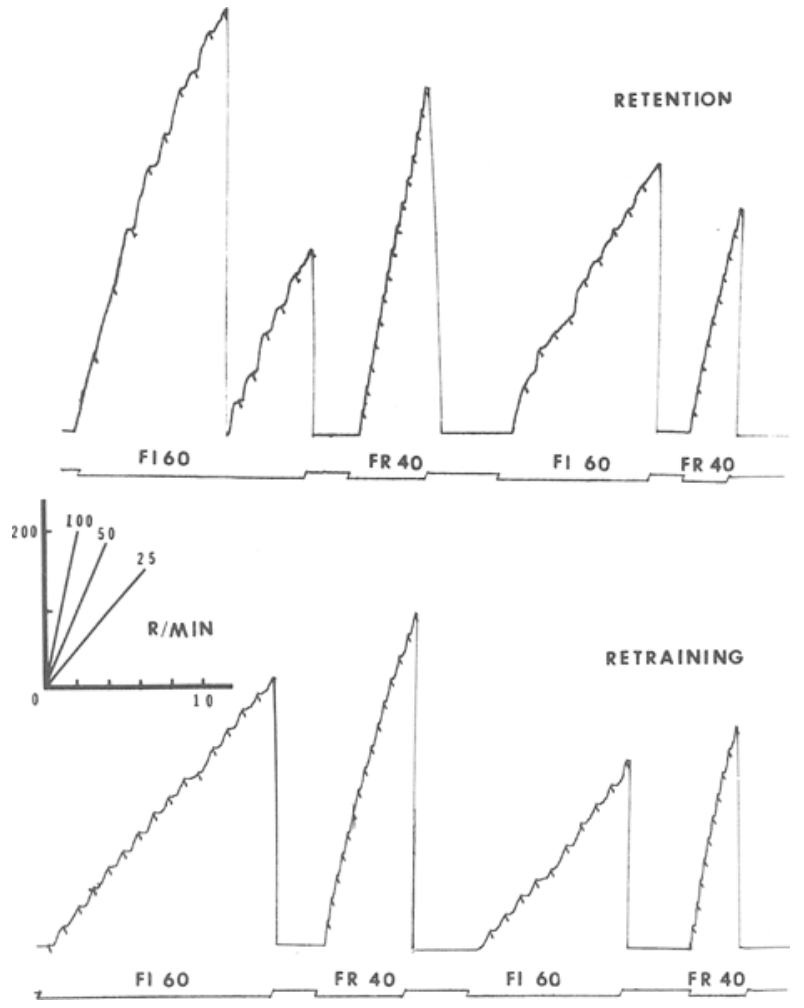

Figure 1. Cumulative records of the keypecking performance of Henry during retention (first session of reexposure to the multiple schedule in the upper record) and during retraining (15th session of reexposure in the lower record). The multiple schedule consisted of alternating blocks of fixed-interval, 60-sec components (FI 60) and fixed-ratio, 40 components (FR 40) separated by periods of extinction when the key light was off. The event lines below each cumulative record indicate the illumination of the green (FI 60) or red (FR 40) key light by a downward displacement. The presentation of food is indicated by a brief downward mark on the cumulative record. The cumulative record was reset after each block of schedules or after approximately 450 responses, whichever came first. The scale of cumulative responses and time, with lines whose slopes correspond to various rates of responding, is indicated by the insert in the left central portion of the figure.

Stimulus control of pecking by the illuminated response key was clearly shown in the cumulative record of the retention test displayed in the upper panel of Figure 1. Prior to the illumination of the key, no pecking occurred, even following three noncontingent food presentations. Immediately upon the onset of the green key signaling the first block of FI schedules, pecking began at a high rate. Pecking continued until the key was darkened, and then it ceased. As shown in the remainder of the upper cumulative record, the rate of responding continued to vary with the presence or absence of the green or red key light for the duration of the retention session.

Stimulus control of pecking by the FI and FR schedules was assessed in two ways: the pause after reinforcement and the average rate of responding. As shown in the upper cumulative record of Figure 1, only brief and slight pausing occurred following the first two reinforcers delivered on the FI 60-sec schedule. Thereafter, pausing became longer and more pronounced, being clearly evident following 11 of the last 13 reinforcers in the initial block of FI schedules. With the beginning of the initial block of FR schedules, brief but pronounced pausing was consistently observed. In contrast to the FI schedules, in which pausing was most often followed by a gradual acceleration to the terminal rate, pausing in the FR schedules was typically followed by a rapid transition to the terminal rate. In the second block of FI schedules, the pattern of responding became more variable, with pausing less pronounced and consistent. The pattern of responding in the second biock of FR schedules was much the same as in the first block.

Consider now the average rate of responding as a measure of schedule control. The overall rates were clearly higher during the blocks of FR than during the blocks of FI schedules. However, the initial exposure to the FI schedule produced a high rate of approximately $100 \mathrm{pecks} / \mathrm{min}$, the rate that was sustained throughout the FR schedule. The average rate during the FI schedule progressively declined as the session continued. During the last six FIs of the initial block, the rate fell to just under 50 pecks/min; during the second FI block, the rate declined still further to approximately 40 pecks $/ \mathrm{min}$.

Schedule control during the retention session may be compared to that shown in the lower panel of Figure 1. After 15 relearning sessions, pausing consistently occurred after every reinforcer and was more pronounced during the blocks of FI schedules. As in the retention session, the transition to the terminal rate was often more gradual following reinforcers delivered according to the FI than the FR schedule. A further similarity to the retention session was the higher average rate during the FR than during the FI schedules. Throughout the 15 th retraining session, the rate during the blocks of FI schedules averaged about 25 pecks $/ \mathrm{min}$, whereas the rate during the FR blocks averaged approximately 75 pecks/ min. Both of these values were somewhat below the rates observed during the retention session.

\section{DISCUSSION}

Within the limitations imposed by the fact that the data arose from a demonstration rather than a formal experiment, clear evidence of stimulus control by the illuminated key and of schedule control by FI and FR schedules was shown over a 12-year retention interval. Stimulus control of pecking by the presence or absence of the key light was complete, in that responses were observed only when the key was illuminated. Schedule control of pecking was present, as shown by the rapid appearance of postreinforcement pausing and differential rates of responding during the FI and FR schedules. Although the distinctive characteristics of the pattern of responding became more pronounced with retraining, the "scalloped" pattern of the FI schedules and the "break-and-run" pattern of FR 
schedules were quickly evident during the retention session. It should be noted that pausing after reinforcement is not found upon the first exposure of naive animals to FI and FR schedules. The first exposure more typically leads to an increase in rate immediately after reinforcement, followed by a decreasing rate as subsequent responses fail to produce a reinforcer (Ferster \& Skinner, 1957).

This report is, of course, not the first to demonstrate very long-term retention of a learned response in an infrahuman organism, although it may be unique in the length of the interval and the existence of schedule control. Using classical training procedures, retention has been shown for 6 months of an eyelid response in dogs (Hilgard \& Marquis, 1935) and for 2 years of a leg flexion response in sheep (Liddell, James, \& Anderson, 1934) (see also Razran, 1939). Using instrumental or operant procedures, retention has been reported for 28 days of a running response in rats (Gagné, 1941), for 150 days of learning set in myna birds (Kamil \& Hunter, 1970; see also Bessemer, 1966), and for 4 years of a discriminated pecking response in pigeons (Skinner, 1950) (see Brogden, 1951, for a review of retention of maze learning). Using hybrid procedures, retention of avoidance responses have been demonstrated over periods of 30 days for rats (Hunter, 1935), 6 months for dogs (Kellogg \& Wolf, 1939), and 2.5 years for dogs (Wendt, 1937). Conditioned emotional responses have been demonstrated for 90 days in rats (Gleitman \& Holmes, 1967) and for 3 years in pigeons (Hoffman, Fleshler, \& Jensen, 1963) (see also Thomas \& Riccio, 1979).

Collectively, the major thrust of both the present demonstration and previous investigations is that animal memory is durable and little affected by the mere passage of time. It appears that the explanatory burden for the analysis of memory must be borne by the environmental events that transpire as time passes, and not by unobserved physiological and conceptual processes that are presumed to covary with the passage of time alone.

\section{REFERENCES}

BESSEMER, D. Retention of object discriminations by learning-set experienced monkeys. Unpublished doctoral dissertation, University of Wisconsin, 1966.

Brogden, W. J. Animal studies of learning. In S. S. Stevens
(Ed.), Handbook of experimental psychology. New York: Wiley, 1951.

Ferster, C. B., \& Skinner, B. F. Schedules of reinforcement. New York: Appleton-Century-Crofts, 1957.

GAGNÉ, R. M. The retention of a conditioned operant response. Journal of Experimental Psychology, 1941, 29, 296-305.

Gleitman, H., \& Holmes, P. Retention of incompletely learned CER in rats. Psychonomic Science, 1967, 7, 19-20.

Hilgard, E. R., \& Marquis, D. G. Acquisition, extinction, and retention of conditioned lid responses to light in dogs. Journal of Comparative Psychology, 1935, 19, 29-58.

Hoffman, H. S., Fleshler, M., \& Jensen, P. Stimulus aspects of aversive controls: The retention of conditioned suppression. Journal of the Experimental Analysis of Behavior, 1963, 6, 575-583.

Hunter, W. S. Conditioning and extinction in the rat. British Journal of Psychology, 1935, 6, 135-148.

Kamil, A. C., \& Hunter, M. W., III. Performance of objectdiscrimination learning set by the Greater Hill myna (Gracula religiosa). Journal of Comparative and Physiological Psychology, 1970, 73, 68-73.

Kellogg, W. N., \& Wolfe, I. S. The nature of the response retained after several varieties of conditioning in the same subjects. Journal of Experimental Psychology, 1939, 24, 366-383.

Liddell, H. S., JAmes, W. T., \& ANDE RSON, O. D. The comparative physiology of the conditioned motor reflex based on experiments with the pig, dog, sheep, goat, and rabbit. Comparative Psychology Monographs, 1934, 11(Whole No. 1).

Razran, G. H. S. Studies in configural conditioning. VI. Comparative extinction and forgetting of pattern and of singlestimulus conditioning. Journal of Experimental Psychology, $1939,24,432-438$.

Skinner, B. F. Are theories of learning necessary? Psychological Review, 1950, 57, 193-216.

Thомаs, D. A., \& Riccio, D. C. Forgetting of a CS attribute in a conditioned suppression paradigm. Animal Learning \& Behavior, 1979, 7, 191-195.

WENDT, G. R. Two and one-half year retention of a conditioned response. Journal of General Psychology, 1937, 17, 178-180.

(Received for publication December 23, 1981.) 